\title{
NOTA
}

\section{APTIDÃO PARA REFLORESTAMENTO DAS SUB-BACIAS DOS CANAIS DO MANGUE E DO CUNHA, MUNICÍPIO DO RIO DE J ANEIRO(1)}

\author{
J oão Bosco Vasconcellos Gomes ${ }^{(2)}$, J osé Francisco Lumbreras ${ }^{(3)}$, R. P. de \\ Oliveira $^{(3)}$, Silvio Barge Bhering ${ }^{(3)}$, M. J . Zaroni ${ }^{(3)}$, Aluisio Granato \\ de Andrade $^{(3)} \&$ Sebastião Barreiros Calderano(3)
}

\begin{abstract}
RESUMO
Avaliou-se a aptidão para reflorestamento das terras das partes não edificadas da vertente norte do maciço da Tijuca, sub-bacias dos canais do Mangue e do Cunha, com o intuito de subsidiar ações do Programa Mutirão Reflorestamento da Secretaria Municipal de Meio Ambiente do Rio de J aneiro. A avaliação da aptidão das terras estimou graus de limitação dos parâmetros: deficiência de nutrientes, deficiência de água, susceptibilidade à erosão e impedimentos ao manejo. Estes graus de limitação foram estimados para os componentes das unidades de mapeamento de solos, considerando as informações de solos e paisagens do mapeamento existente. Para a di gitalização e organização das infor mações geradas, foram utilizados sistemas de informações geográficas. As seguintes classes de aptidão para reflorestamento foram determi nadas: $11,2 \%$ de Regular, $81,5 \%$ de Restrita e 7,3\% de Inapta. A declividade representa o fator limitante de maior importância para as terras da classe de apti dão restrita, seguida da presença de rochosidade.
\end{abstract}

Termos de indexação: avaliação de terras, uso da terra, geoprocessamento.

\footnotetext{
(1) Recebido para publicação em setembro de 2003 e aprovado em março de 2005.

(2) Pesquisador da Embrapa Tabuleiros Costeiros. Av. Beira-Mar 3250, CEP 49025-040 Aracaju (SE). E-mail: bosco@cpatc.embrapa.br

(3) Pesquisador da Embrapa Solos. Rua J ardim Botânico 1024, CEP 22460-000 Rio deJ aneiro (RJ ). E-mails: jflum@cnps.embrapa.br; ronaldo@cnps.embrapa.br; silvio@cnps.embrapa.br; zaroni@cnps.embrapa.br; aluisio@cnps.embrapa.br; sebast@cnps.embrapa.br
} 


\title{
SUMMARY: SUITABILITY FOR REFORESTATION OF THE CANAL DO CUNHA AND CANAL DO MANGUE WATERSHEDS, STATE OF RIO DE J ANEIRO
}

\begin{abstract}
Thesuitability for reforestation of parts of the N orth Slope of theTijuca neighborhood not covered by buildings, the Mangue and Cunha watersheds, was studied. The plan was to subsidize the "Mutirão" Reforestation Program of the Environmental Department of Rio deJ aneiro Municipality. Nutrient deficiency, water deficiency, erosion susceptibility and management impediments were considered in the evaluation of land suitability. The limitation degrees were evaluated for the components of soil survey units, consi dering soil and landscape information from the available maps. Geographical information systems wereused for data input, geoprocessing and results presentation. Thestudied area presented the following distribution of suitability classes for reforestation: $11.2 \%$ regular, $81.5 \%$ restricted and $7.3 \%$ unsuitable. Slope is the most limitant factor in the restricted class followed by the presence of rocks.
\end{abstract}

Index terms: Iand evaluation, land-use, geoprocessing.

\section{NTRODUÇÃO}

Levantamentos de solos representam um inventário de informações ambientais que estabel ecem uma basecientífica para o planejamento do uso da terra. Interpretações sobre o uso de cada unidade de mapeamento atendem os mais diversos fins: agropecuária, engenharia, locação de áreas de empréstimo, manejo florestal, desenvolvimento urbano, dentre outros (Miller \& Donahue, 1990).

O Programa Mutirão Reflorestamento vem tentando promover, ao longo dos últimos 15 anos, o reflorestamento das encostas e dos manguezais da cidade do Rio de J aneiro. A restauração de ambientes naturais degradados, a recomposição da cobertura florestal do município e a ampliação da oferta de trabal ho em áreas favelizadas estão entre os principais objetivos deste Programa. Segundo dados da Secretaria Municipal de Meio Ambiente do Rio de J aneiro (SMAC), através do Programa foram reflorestados aproximadamente 1.400 ha, atendendo a 94 comunidades distribuídas pela cidade, com uma população diretamente beneficiada estimada em 280 mil pessoas. O total de mudas plantadas nos 15 anos do Programa Mutirão Reflorestamento é superior a 3,1 milhões (Programa..., 2003).

Com o intuito de subsi diar ações deste programa, a SMAC e a Embrapa Solos realizaram o projeto “Mapeamento pedológico e interpretações úteis ao planejamento ambiental do município do Rio de J aneiro". U ma das ações do projeto engl obou estudos mais detalhados de áreas-piloto, onde vêm sendo realizadas ações de reflorestamento do Programa Mutirão. São el as formadas por paisagens do maciço da Tijuca e do morro dos Macacos (serra do Engenho Novo). Essas paisagens apresentam extensa área florestada, relevo acidentado efreqüente pressão por ocupação. A forte vulnerabilidade da área pode ser adiantada a partir de estudo na escala 1:50.000, quando todas as terras foram consideradas inaptas para uso agrícola (Palmieri \& Santos, 1980). Representam grandes áreas de preservação encravadas no coração urbano da metrópole, que exigem ações múltiplas por parte do executivo e, na área agronômica, uma ação eficaz de reflorestamento de encostas.

O objetivo do presente estudo foi avaliar a aptidão das terras, realizada especificamente para reflorestamento, das partes não edificadas da vertente norte do maciço da Tijuca, sub-bacias dos canais do Mangue e do Cunha (escala 1:20.000), utilizando, como informação básica, o "Levantamento semidetal hado de solos das subbacias do Canal do Mangue e do Canal do Cunha, município do Rio deJ aneiro, RJ " (Embrapa, 1999).

\section{MATERIAL E MÉTODOS}

A área de estudo engloba a parte não edificada das sub-bacias do canal do Mangue e do canal do Cunha, inseridas na bacia da Baía da Guanabara, e abarca a Serra do Engenho N ovo e a vertente norte do Maciço da Tijuca. Situa-se entre as coordenadas UTM 7.459.000 e 7.467.000 m N e 671.500 e $685.000 \mathrm{~m} \mathrm{E}$, no município do Rio de J aneiro, RJ (F igura 1 ). A área efetivamente mapeada abrange 2.402,8 ha, o que representa cerca de $2 \%$ da área total do município e 3,5 \% de sua área não-urbana.

A geol ogia é constituída predominantementepor rochas gnáissicas, pré-cambrianas, de constituição variada (Heilbron et al., 1993). O rel evo éassociado aos domínios fisiográficos do maciço da Tijuca e da serra do Engenho N ovo. Esta última constitui uma col ina isolada na planície sedimentar da baixada de 
Inhaúma. O clima local apresenta grande irregularidade, sobretudo no que diz respeito à pluviosidade, destacando-se a influência do maciço da Tijuca em relação aos eventos pluviais intensos. As isoietas ao longo das sub-bacias variam de 1.100 a $1.400 \mathrm{~mm}$. O ano de 1993 registrou valor superior a $2.100 \mathrm{~mm}$ nas partes mais elevadas do maciço (Anuário, 1995). A temperatura média anual varia de $24,9 \stackrel{\circ}{ } \mathrm{C}$, nas partes mais baixas do município (estação Bangu) a 21,6 C, na estação Alto da Boa Vista, a 347 m de altitude (Agência..., 2003). Nas sub-bacias, os locais mais quentes estão relacionados com a serra do Engenho Novo e com os sopés das encostas, principalmente na sub-bacia do Canal do Cunha, apresentando clima tropical com verão chuvoso e inverno seco, do tipo Aw na classificação de Köppen. As temperaturas mais amenas ocorrem nas partes mais el evadas do maciço, acima de $500 \mathrm{~m}$ de altitude, com clima do tipo Cfa, de verão quente e sem estação seca definida (Anuário..., 1995). A maior parte da área cor responde ao Parque Nacional da Tijuca eencontra-se com cobertura vegetal densa, de elevado porte, com muitas espécies nativas. 0 capim-colonião avança nas áreas urbanizadas e favelizadas e aumenta o risco de fogo nos limites das áreas de mata.
A avaliação da aptidão das terras foi adaptada de Ramalho Filho \& Beek (1994) e usada para interpretar o levantamento semidetal hado de solos da área de estudo, escala 1:20.000 (E mbrapa, 1999). O referido mapeamento contou com 24 perfis de solo e 41 prospecções (tradagens e registros em barrancos) e definiu 10 unidades de mapeamento e dois tipos de terreno.

\section{Sistema de manejo considerado e premissas básicas}

O reflorestamento de encostas idealizado pelo Programa Mutirão da prefeitura do Rio de J aneiro é bastante abrangente, envol vendo recuperação do ecossistema original da Mata Atlântica, estabilização do solo, limitação do crescimento das comunidades sobre as áreas de risco ou de proteção ambiental da cidade, redução da ocorrência de enchentes, criação de espaços de lazer e de educação ambiental próximos às áreas carentes, proteção e revitalização dos mananciais hídricos e criação de corredores ecológicos para a fauna (Objetivos..., 2003).

O sistema está dividido em duas etapas: instalação e manutenção. A primeira etapa envolve

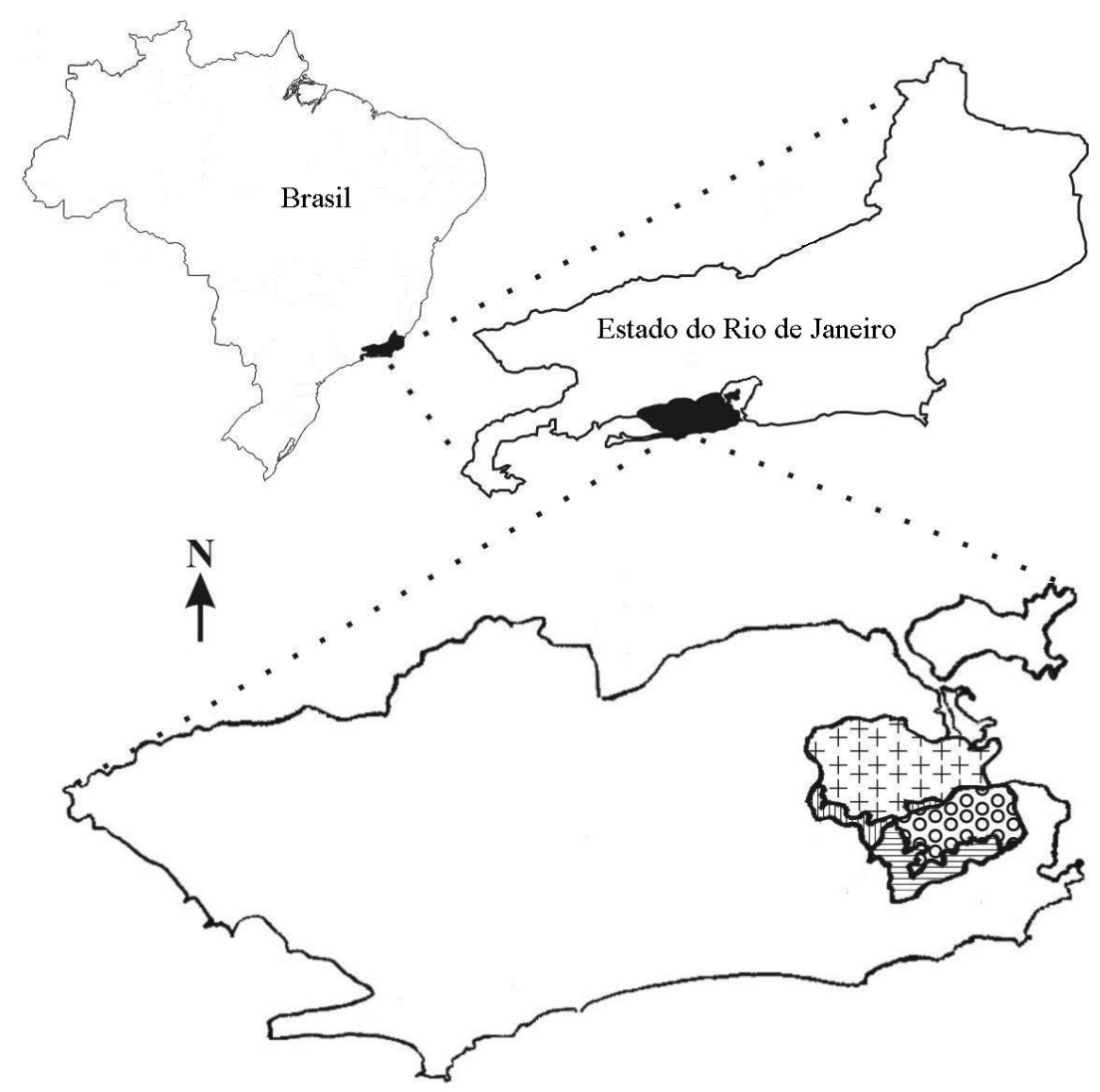

Figura 1. Localização e mapa do município do Rio de J aneiro, mostrando as sub-bacias dos canais do Cunha (linhas verticais, para área mapeável, e sinais em cruz, para área urbanizada) e do Mangue (linhas horizontais, para área mapeável, e círculos, para área urbanizada). 
o conjunto das operações de campo que compreendem desde a preparação do terreno até o plantio. A manutenção compreende as seguintes operações: limpeza de aceiros, roçada, replantio, adubação de cobertura, combate às pragas, desbastes e podas. (Desenvolvimento, 2003). O sistema envolve o plantio de espécies arbóreas, que contribui para a melhoria da qualidade ambiental, sabendo-se da pluralidade de objetivos que esse plantio pode ter. Estão previstos melhoramentos da deficiência de nutrientes/fertilidade dos solos, com adubações na cova de plantio e por cobertura. A instalação e os tratos culturais não envol vem o uso de mecanização.

\section{Graus de limitação}

O sistema estimou graus de limitação (desvios) de quatro parâmetros que sintetizam as qualidades de um ecossistema, adaptando conceitos de Resende et al. (2002): deficiência de nutrientes/fertilidade $(\Delta \mathrm{N})$, deficiência de água $(\Delta \mathrm{H})$, susceptibilidade à erosão $(\Delta \mathrm{E})$ e impedimentos ao manejo $(\Delta \mathrm{M})$. O parâmetro excesso de água/deficiência de oxigênio não apresentou desvios na área de estudo, formada por terras altas.

As regras que definiram os graus de limitação de uso das terras foram incorporadas como funções lógicas numa planilha el etrônica. Para elas foram utilizandos os atributos disponíveis a partir do mapeamento existente, que reflitam diferenças na qualidade das terras para o objetivo proposto.
$\mathrm{O} \Delta \mathrm{N}$ é definido pela saturação por bases e pela relaçãoAl/bases. O grau delimitação podeser Ligeiro, Moderado eF orte, o que corresponde ao componente da unidade de mapeamento, respectivamente, eutrófico, distrófico e álico.

$\mathrm{O} \Delta \mathrm{H}$ foi inferido pela fase de vegetação natural de cada componente, substituindo a ausência de dados hídricos do solo (E mbrapa, 1988) que permitissem o cálculo do balanço hídrico para os perfis de solo representativos de cada componente das unidades do mapeamento. Podem ocorrer os graus de limitação Nulo/Ligeiro e Ligeiro, que correspondem, respectivamente, às fases de vegetação flor esta tropical subperenifólia efloresta tropical subcaducifólia.

Os parâmetros $\Delta \mathrm{E}$ e $\Delta \mathrm{M}$ são avaliados conjuntamente, por ocorrerem de forma semel hante na área de estudo, onde as terras mais íngremes e rochosas são aquelas de maior risco de erosão e, normalmente, de mais difícil acesso e tráfego de pessoas. A definição da regra do grau de limitação por $\Delta \mathrm{E} / \Delta \mathrm{M}$ (Quadro 1) ainda considera, além da fase de rochosidade e do rel evo, a profundidade do sólum.

O conjunto de regras, além de servir à definição das classes deaptidão agrícol a das terras, servecomo uma chave (Resende et al., 2002) contextualizada ao universo de sol os locais eà infor mação disponível.

\section{Viabilidade de melhoramento da deficiência de nutrientes/fertilidade}

O mel horamento necessário aos solos eutróficos da área de estudo, originalmente com $\Delta \mathrm{N}$ Ligeiro,

Quadro 1. Definição do grau de limitação por susceptibilidade à erosão/impedimentos ao manejo $(\Delta E / \Delta M)$, vertente norte do maciço da Tijuca, sub-bacias dos canais do Mangue e do $C$ unha, $R$ io de J aneiro (RJ )

\begin{tabular}{|c|c|c|c|}
\hline \multirow[b]{2}{*}{$\Delta \mathbf{E} / \Delta \mathbf{M}$} & \multicolumn{3}{|c|}{ Característica do componente da unidade de mapeamento de solos } \\
\hline & Fase de rochosidade(1) & $\begin{array}{l}\text { Profundidade } \\
\text { mínima do sólum }\end{array}$ & Relevo \\
\hline Nulo a Moderado & $\begin{array}{l}\text { Ligeiramente rochosa, } \\
\text { ou não-rochosa }\end{array}$ & $\geq 50 \mathrm{~cm}$ & Plano a ondulado \\
\hline Forte & $\begin{array}{l}\text { Ligeiramente rochosa, } \\
\text { ou não-rochosa }\end{array}$ & $\geq 50 \mathrm{~cm}$ & Forte ondulado \\
\hline F orte/Muito F orte, regra 1 & $\begin{array}{l}\text { Ligeiramente rochosa, } \\
\text { ou não-rochosa }\end{array}$ & $>50 \mathrm{~cm}$ & Forte ondulado a montanhoso \\
\hline F orte/M uito F orte, regra 2 & $\begin{array}{l}\text { Ligeiramente rochosa, } \\
\text { ou não-rochosa }\end{array}$ & $>50 \mathrm{~cm}$ & Montanhoso \\
\hline Muito F orte, regra 1 & $\begin{array}{l}\text { Ligeiramente rochosa, } \\
\text { ou não-rochosa }\end{array}$ & $=50 \mathrm{~cm}$ & F orte ondulado a montanhoso \\
\hline Muito Forte, regra 2 & $\begin{array}{l}\text { Ligeiramente rochosa, } \\
\text { ou não-rochosa }\end{array}$ & $=50 \mathrm{~cm}$ & Montanhoso \\
\hline Muito Forte, regra 3 & Rochosa & $=50 \mathrm{~cm}$ & Forte ondulado \\
\hline
\end{tabular}

${ }^{(1)}$ Rochosa: quando os afloramentos ou matacões ocupam de 25 a 50 \% da superfície do terreno; ligeiramente rochosa: quando os afloramentos ou matacões ocupam de 2 a $10 \%$ da superfície do terreno. 
Quadro 2. Guia da classificação de aptidão para reflorestamento das terras da vertente norte do maciço da Tijuca e das sub-bacias dos canais do Mangue e do Cunha, Rio deJ aneiro (RJ ). 0 grau de limitação colocado é o mais restritivo que cada fator pode alcançar para determinada classe de aptidão

\begin{tabular}{clll}
\hline \multicolumn{1}{c}{$\mathbf{N}$} & \multicolumn{1}{c}{$\Delta \mathbf{H}$} & \multicolumn{1}{c}{$\mathbf{E} / \Delta \mathbf{M}$} & Classe de aptidão(1) \\
\hline N ulo/Ligeirob & N ulo/Ligeiro & Moderado & Boa \\
Ligeirob $\underline{b}$ & Ligeiro & Forte & Regular \\
Ligeirob & Ligeiro & Extremamente Forte & Restrita \\
\hline
\end{tabular}

(1) Os afloramentos de rocha e as áreas de mineração constituem terras I naptas para o reflorestamento.

prioriza a adubação orgânica e de $\mathrm{P}$ na cova de plantio, por eles apresentarem boa reposição de bases trocáveis e serem isentos de toxidez por Al. I sso corresponde à classe de melhoramento "a", viável com práticas simples e de pequeno custo, de forma que sol os com $\Delta \mathrm{N}$ Ligeiro irão para $\Delta \mathrm{N}$ Nuloa.

Para as áreas de solos distróficos e álicos (respectivamente $\Delta \mathrm{N}$ Moderado e $\Delta \mathrm{N}$ Forte), o planejamento deve consi derar custos de correção um pouco mais elevados, principalmente de calagem. I sso correspondeà classe de mel horamento " $b$ ", viável com práticas intensivas e de custo considerável. Sol os original mente com $\Delta N$ M oderado irão para $\Delta N$ Nulo/Ligeirob e solos originalmente com $\Delta \mathrm{N}$ Forte irão para $\Delta \mathrm{N}$ Ligeirob.

\section{Classes de aptidão para reflorestamento}

De posse dos desvios de cada fator de limitação, já levando em conta a possibilidade de melhoramento do $\Delta \mathrm{N}$, utilizou-se uma matriz de conversão (Quadro 2), para determinar a classe de aptidão do sistema de manejo reflorestamento de cada faixa de terra (componentes das unidades de mapeamento de solos), indicando qual fator ou fatores limitantes definem a classe de aptidão al cançada.

Tendo em mente que a finalidade da atividade não é econômica, mas, sim, de incrementar a qualidade ambiental, as únicas fatias de terra consi deradas de aptidão I napta são os afloramentos

Quadro 3. Simbologia correspondente às classes de aptidão para reflorestamento, vertente norte do maciço da Tijuca, sub-bacias dos canais do Mangue e do Cunha, Rio de J aneiro (RJ )

\begin{tabular}{cc}
\hline Classe de aptidão & Símbolo da classe \\
\hline Boa & $\mathrm{R}$ \\
Regular & $\mathrm{r}$ \\
Restrita & $(\mathrm{r})$ \\
Inapta & $\mathrm{I}$ \\
\hline
\end{tabular}

de rocha eas áreas de mineração. As demais terras podem pertencer às classes de aptidão Boa, Regular ou Restrita para o sistema de manejo considerado.

\section{Simbologia das classes de aptidão para reflo- restamento}

O sistema de símbolos para o sistema de manejo reflorestamento está no quadro 3. Os fatores limitantes para determinada faixa de terra são expressos por letras minúsculas ao lado do símbolo da classe, conforme critérios estabelecidos no quadro 4. Optou-se por utilizar as características declividade, presença derochosidade e profundidade mínima de sólum substituindo o fator de limitação $\Delta E / \Delta M$. Dessa forma, procurou-se ser mais específico, aproveitando melhor a escala de trabal ho disponível nas sub-bacias, convergindo para os seus reais problemas. Os tipos de terreno também apresentam símbolo próprio.

\section{Sistemas geográficos de informação (SIGs)}

O mapa de solos foi digitalizado em base planialtimétrica fornecida pela SMAC e reclassificado a partir das regras definidas pelo sistema de avaliação da aptidão para reflorestamento descrito. Os SI Gs utilizados para a digital ização e organização das informações geradas foram os sistemas Arc-Info, ArcView, ESRI I LWIS (ITC) e SGI-VGA (E ngespaço).

\section{RESULTADOS E DISCUSSÃO}

A classe deaptidão Boa para reflorestamento não ocorreu na área estudada (Quadro 5). Essa ausência da classe Boa reflete um $\Delta \mathrm{E} / \Delta \mathrm{M}$ mais restritivo do que Moderado para todas as terras estudadas, ou seja, terras com relevo forte ondulado ou mais íngreme.

\section{Aptidão para reflorestamento das unidades de mapeamento}

Asterras com aptidão Regular para reflorestamento $(r / h p)$, Argissolos Vermelho-Amarelos e 
Cambissolos Háplicos de relevo forte ondulado (Quadro 5), correspondem a 268,4 ha (11,2 \% da área total mapeada) e escapam da classe Restrita por apresentarem a fase de relevo menos declivosa da área estudada (Quadro 6 e Figura 2). Estas terras, em sua maioria localizadas na serra do Engenho Novo e com limitações por espessura e, em grande parte, com boa reserva de nutrientes, podem ser consideradas de maior risco quanto à ocorrência de fogo. O problema é potencializado pela presença do capim-col onião em áreas desmatadas, sendo comum a passagem do fogo das áreas de colonião para a mata, áreas de reflorestamento e mesmo áreas urbanizadas. Nesse sentido, o acei ro periódico éuma

Quadro 4. Critérios de ocorrência e si mbologia correspondente aos fatores limitantes que acompanham os símbolos das classes de aptidão para reflorestamento, vertente norte do maciço da Tijuca, subbacias dos canais do Mangue e do Cunha, Rio de J aneiro (RJ )

\begin{tabular}{|c|c|c|}
\hline F ator limitante / tipo de terreno & Critério & $\begin{array}{c}\text { Símbolo do } \\
\text { fator limitante }\end{array}$ \\
\hline Deficiência de nutrientes/fertilidade & Solos álicos & $f$ \\
\hline Deficiência de água & Vegetação nativa de floresta tropical subcaducifólia & $\mathrm{h}$ \\
\hline Declividade (classe de relevo) & Relevo montanhoso à escarpado & $d$ \\
\hline Rochosidade & Caráter rochoso & r \\
\hline Espessura mínima do sólum & $50 \mathrm{~cm}$ & $\mathrm{p}$ \\
\hline Afloramentos de rocha e áreas de mineração & - & ar \\
\hline
\end{tabular}

Quadro 5. Graus de limitação após redução dos desvios, classes de apti dão para reflorestamento e fatores limitantes dos componentes das unidades de mapeamento de solos das terras da vertente norte do maciço da Tijuca, sub-bacias dos canais do Mangue e do Cunha, Rio de J aneiro (RJ )

\begin{tabular}{|c|c|c|c|c|c|c|}
\hline \multicolumn{2}{|c|}{$\begin{array}{c}\text { Unidade de } \\
\text { mapeamento de solo }\end{array}$} & \multicolumn{3}{|c|}{ Grau de limitação } & \multirow{2}{*}{ Classe aptidão } & \multirow{2}{*}{ Fator limitante(2) } \\
\hline Símbolo(1) & Componente ${ }^{(1)}$ & $\Delta \mathbf{N}$ & $\Delta \mathbf{H}$ & $\Delta \mathbf{E} / \Delta \mathbf{M}$ & & \\
\hline LVAd(3) & LVA & Ligeirob & Nulo/Ligeiro & Forte/Muito Forte & $(r)$ & $\mathrm{fd}$ \\
\hline $\operatorname{LVAd}^{(3)}$ & $C X$ & Ligeirob & Nulo/Ligeiro & F orte/Muito F orte & $(r)$ & $\mathrm{fd}$ \\
\hline PVAd1(3) & PVA & Ligeirob & Ligeiro & F orte/Muito F orte & $(r)$ & fhd \\
\hline PVAd(2) & PVA & Nulo/Ligeirob & Ligeiro & Forte & $r$ & hp \\
\hline PVAd(2) & $C X$ & Nuloa & Ligeiro & Forte & $r$ & $\mathrm{hp}$ \\
\hline $\mathrm{CXbd} 1^{(3)}$ & $C X$ & Ligeirob & Ligeiro & Muito Forte & $(r)$ & fhdp \\
\hline $\mathrm{CXbd2}(3)$ & $C X$ & Ligeirob & Ligeiro & Extremamente F orte & $(r)$ & fhdrp \\
\hline $\mathrm{CXbd} 3^{(3)}$ & $C X$ & Ligeirob & Nulo/Ligeiro & Extremamente F orte & $(r)$ & fdrp \\
\hline CXbel & $c x$ & Nuloạ & Ligeiro & Forte & r & $\mathrm{hp}$ \\
\hline CXbel & $C X$ & Nulo/Ligeirob & Ligeiro & Forte & $r$ & $\mathrm{hp}$ \\
\hline CXbe2 & $c x$ & Nuloạ & Ligeiro & Muito Forte & $(r)$ & hrp \\
\hline CXbe2 & $c x$ & Nulo/Ligeirob & Ligeiro & Muito Forte & $(r)$ & hrp \\
\hline Cxbe3 & $c x$ & Nuloa & Ligeiro & Muito Forte & $(r)$ & hdp \\
\hline CXbe3 & PVA & Nuloa & Ligeiro & Muito Forte & $(r)$ & hdp \\
\hline CXbe4 & $c x$ & Nuloa & Ligeiro & Extremamente F orte & $(r)$ & hdrp \\
\hline CXbe4 & PVA & Nuloạ & Ligeiro & Extremamente Forte & $(r)$ & hdrp \\
\hline$A R$ & $A R$ & - & - & - & I & ar \\
\hline MI & MI & - & - & - & I & ar \\
\hline
\end{tabular}

(1) Classes de solo/Tipo de terreno: LVA - Latossolo Vermel ho-Amarelo; PVA -Argissolo Vermel ho-Amarelo; CX - Cambissolo Háplico; AR - Afloramento de Rocha; MI - Área de mineração; b - argila de atividade baixa; $d$ - distrófico; e - eutrófico (Embrapa, 1999). (2) f - deficiência de fertilidade; $h$ - deficiência de água; $d$ - declividade; $r$ - rochosidade; $p$ - profundidade do sólum; ar - afloramento de rocha ou área de mineração. ${ }^{(3)}$ Unidade com presença de caráter álico. 
Quadro 6. Símbolo, descrição, unidades de mapeamento, extensão, distribuição percentual e legenda do mapa das classes de apti dão para reflorestamento das terras da vertente norte do maciço da Tijuca, sub-bacias dos canais do Mangue e do Cunha, Rio de J aneiro (RJ )

\begin{tabular}{|c|c|c|c|c|c|}
\hline Símbolo(1) & Descrição & $\begin{array}{c}\text { Unidades de } \\
\text { mapeamento } \\
\text { de solos }\end{array}$ & ha & $\%$ & $\begin{array}{l}\text { Legenda do } \\
\text { mapa }^{(3)}\end{array}$ \\
\hline $\mathrm{r} / \mathrm{hp}$ & $\begin{array}{l}\text { Terras com aptidão regular para reflorestamento, } \\
\text { fatores limitantes deficiência de água e espessura do } \\
\text { sólum. }\end{array}$ & $\begin{array}{l}\text { PVAd2, } \\
\text { CXbe1 }\end{array}$ & 268,4 & 11,2 & \\
\hline$(r) / f d$ & $\begin{array}{l}\text { Terras com aptidão restrita para reflorestamento, } \\
\text { fatores limitantes deficiência de fertilidade e } \\
\text { declividade. }\end{array}$ & LVAd & $1.009,8$ & 42,0 & \\
\hline$(r) /$ fhd & $\begin{array}{l}\text { Terras com aptidão restrita para reflorestamento, } \\
\text { fatores limitantes deficiência de fertilidade e de água } \\
\text { e declividade. }\end{array}$ & PVAd1 & 22,3 & 0,9 & \\
\hline$(\mathrm{r}) / \mathrm{hdp}$ & $\begin{array}{l}\text { Terras com aptidão restrita para reflorestamento, } \\
\text { fatores limitantes defi ciência de água, declividade e } \\
\text { espessura do sólum. }\end{array}$ & CXbe3 & 355,4 & 14,8 & \\
\hline$(\mathrm{r}) / \mathrm{hrp}$ & $\begin{array}{l}\text { Terras com apti dão restrita para reflorestamento, } \\
\text { fatores limitantes deficiência de água, rochosidade e } \\
\text { espessura do sólum. }\end{array}$ & CXbe2 & 22,0 & 0,9 & \\
\hline$(r) / f h d p$ & $\begin{array}{l}\text { Terras com apti dão restrita para reflorestamento, } \\
\text { fatores limitantes deficiência de fertilidade e de } \\
\text { água, declividade e espessura do sólum. }\end{array}$ & CXbd1 & 55,1 & 2,3 & \\
\hline$(r) / f d r p$ & $\begin{array}{l}\text { Terras com aptidão restrita para reflorestamento, } \\
\text { fatores limitantes deficiência de fertilidade, } \\
\text { declividade, rochosidade e espessura do sólum. }\end{array}$ & $\mathrm{CXbd} 3$ & 43,1 & 1,8 & 市 \\
\hline (r)/hdrp & $\begin{array}{l}\text { Terras com aptidão restrita para reflorestamento, } \\
\text { fatores limitantes deficiência de água, declividade, } \\
\text { rochosidade e espessura do sólum. }\end{array}$ & CXbe4 & 238,3 & 9,9 & $\S$ \\
\hline$(r) / f h d r p$ & $\begin{array}{l}\text { Terras com aptidão restrita para reflorestamento, } \\
\text { fatores limitantes deficiência de fertilidade e água, } \\
\text { declividade, rochosidade e espessura do sólum. }\end{array}$ & $\mathrm{CXbd} 2$ & 213,2 & 8,9 & \\
\hline \multirow[t]{2}{*}{ I/ar } & $\begin{array}{l}\text { Terras sem aptidão para reflorestamento. Paisagens } \\
\text { de afloramentos de rocha e áreas de mineração }\end{array}$ & $A R, M I$ & 175,2 & 7,3 & \\
\hline & & TOTAL & 2402,8 & 100,0 & \\
\hline
\end{tabular}

(1) Aptidão referida ao primeiro componente de cada unidade de mapeamento de solos. Classes de aptidão das terras: $\mathrm{R}$ - classe boa para reflorestamento (não ocorre na área); $r$ - classe regular para reflorestamento; $(r)$ - classe restrita para reflorestamento; I classe inapta. Fatores limitantes/tipo de terreno: $f$ - deficiência de nutrientes/fertilidade; $h$ - deficiência de água; $d$ - declividade; $r$ rochosidade; p - profundidade do sólum; ar - afloramento de rocha ou área de mineração. ${ }^{(2)}$ Embrapa (1999). ${ }^{(3)}$ Relativo à figura 2.

prática a ser valorizada no manejo das áreas reflorestadas.

As ter ras classificadas como ( $r$ )/fd foram as mais freqüentes na área de estudo (1.009,8 ha, ou 42 \% da área mapeada). Correspondem a Latossolos Vermelhos-Amarelos e Cambissolos Háplicos de relevo montanhoso, todos localizados no Maciço da Tijuca, boa partenas suas cotas mais altas. As outras classes com aptidão Restrita [(r)/fhd, $(r) / h d p,(r) / h r p$,

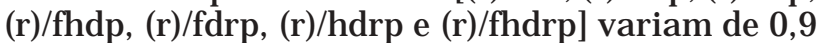
a $14,8 \%$ da área mapeada. Dessa forma, as terras com aptidão Restrita totalizam $81,5 \%$ da área mapeada, resultado que refletea fortevulnerabilidade dos ambientes das sub-bacias. Considerando isoladamente os fatores limitantes, observou-se a importância do fator declividade, presenteem 80,6 \% das terras da área mapeada, lembrando que a presença desse fator no símbolo da aptidão corresponde às terras com relevo montanhoso a escarpado.

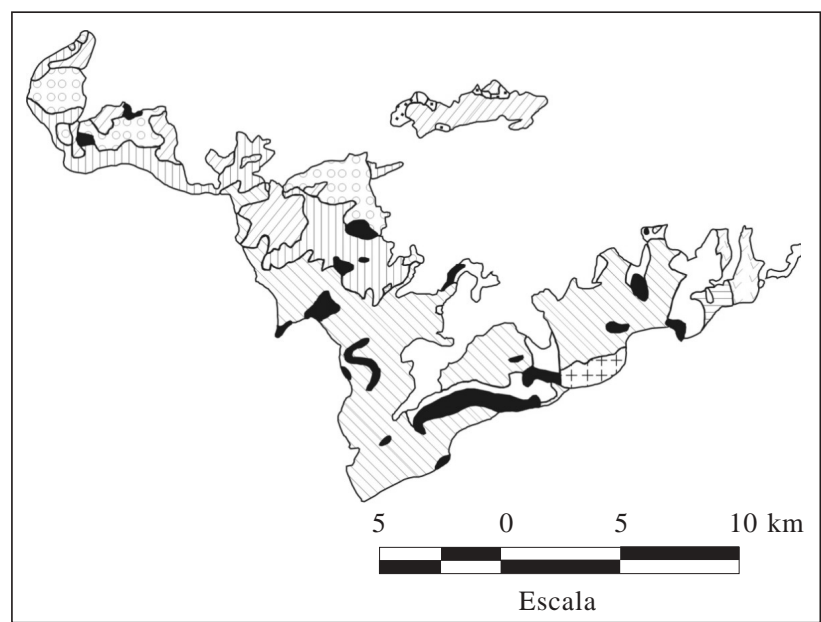

Figura 2. Classes de aptidão para reflorestamento das terras da vertente norte do maciço da Tijuca, sub-bacias dos canais do Mangue e do Cunha, Rio deJ aneiro (RJ ) (comodefinidas no Quadro 6). 


\section{CONCLUSÕES}

1. As terras da área estudada apresentaram a seguinte distribuição de classes de aptidão para reflorestamento: $11,2 \%$ de Regular, $81,5 \%$ de Restrita e 7,3\% de I napta.

2. Não foram registradas terras da classe de aptidão Boa para reflorestamento na área de estudo, em decorrência de desvios por susceptibilidade à erosão e deimpedimentos ao manejo mais restritivos do que moderados para todas as terras estudadas.

3. As limitações por declividade representaram 80,6 \% das terras da área mapeada e constituíram o fator limitante de maior importância da área de estudo, seguido da presença de rochosidade e de sólum com espessura mínima de $50 \mathrm{~cm}$.

\section{LITE RATURA CITADA}

AGÊNCIA NACIONAL DE ÁGUAS. Disponível em: বhttp:// www.hidroweb.ana.gov.br/>. Acesso em 16 jul. 2003.

ANUÁRI O Estatístico da Cidade do Rio de J aneiro 1993/94. Rio de J aneiro, IPLAN-RIO, 1995. 1v.

DESENVOLVIMENTO. Disponível em: <http:// www.rio.rj.gov.br/smac/mostra_subnoticia.php? not $=P E P \&$ codnot $=38 \&$ cod_sub_not $=13>$. Acesso em 24 mar. 2003.

EMPRESA BRASILEIRA DE PESQUISA AGROPECUÁRIA EMBRAPA. Levantamento semidetalhado de sol os das subbacias dos canais do Mangue e do Cunha, município do Rio de J aneiro, RJ . In: Empresa Brasileira de Pesquisa Agropecuária. Mapeamento pedológico e interpretações úteis ao planejamento ambiental das sub-bacias dos canais do Mangue e do Cunha, Município do Rio de J aneiro, RJ . Rio deJ aneiro, Embrapa Solos, 1999. 194p. (RelatórioTécnico)
EMPRESA BRASILEIRA DE PESQUISA AGROPECUÁRIA EMBRAPA. Serviço Nacional de Levantamento e Conservação de Solos. Critérios para distinção de classes de solos e de fases de unidades de mapeamento; normas em uso pelo SNLCS. Rio de Janeiro, 1988. 67p. (Documentos, 11)

HEILBRON, M.; VALERIANO, C.M. \& BESSA, M.P. Litoestratigrafia, evolução tectono-metamórfica e magmatismo no Pré-Cambriano do setor sudeste do Município do Rio de Janeiro. In.: SIMPÓSIO DE GEOLOGIA DO SUDESTE, 3., Rio deJ aneiro, 1993. Atas. Rio de J aneiro, Sociedade Brasileira de Geologia, 1993. p.174-179.

MILLER, R.W. \& DONAHUE, R.L. Soils: an introduction to soils and plant growth. 6.ed. Englewood Cliffs, Prentice Hall, 1990. 768p.

OBJETIVOS DO PROGRAMA. Disponível em: <http:// w w w $r$ i o.r j.g o v. b r / s m a c / mostra_subnoticia.php?not $=P E P \&$ codnot $=38 \&$ cod_sub_not $=12>$. Acesso em 24 mar. 2003.

PALMIERI, F. \& SANTOS, H.G. Levantamento semidetal hado e aptidão agrícola dos sol os do município do Rio deJ aneiro. Rio de J aneiro, Embrapa/SNLCS, 1980. 389p. (Boletim Técnico, 66)

PROGRAMA MUTIRÃO REFLORESTAMENTO. Disponível em: \http://www.rio.rj.gov.br/ smac/>. Acesso em 24 mar. 2003.

RAMALHO FILHO, A. \& BEEK, K.J. Sistema de avaliação da aptidão agrícola das terras. 3. ed. rev. Rio de J aneiro, Embrapa, Centro Nacional de Pesquisa de Solos, 1994. 65p.

RESENDE, M.; CURI, N.; REZENDE, S.B. \& CORRÊA, G.F. Pedologia: base para distinção de ambientes. Viçosa, Universidade Federal de Viçosa/NEPUT, 2002. 338p. 